\title{
Detection of PirA/B Toxin Genes for Acute Hepatopancreatic Necrosis Disease (AHPND) and Vibrio parahaemolyticus in Penaeus vannamei Culture from Major White Shrimp Producing Farms in Malaysia
}

\author{
Bakar Padilah ${ }^{1 *}$, Yahya Rohaiza-Asmini', Han-Ming Gan², Wan Ahmad Wan \\ Rozana $^{1}$, Wan Muhammad Hazim Wan Sajiri ${ }^{1}$ and Beng-Chu Kua ${ }^{1}$ \\ ${ }^{1}$ National Fish Health Research Division, Fisheries Research Institute (FRI), 11960 Batu Maung, Penang, \\ Malaysia \\ ${ }^{2}$ School of Science, Monash University Malaysia, Jalan Lagoon Selatan, Bandar Sunway 47500, Petaling \\ Jaya, Selangor, Malaysia
}

\begin{abstract}
The acute hepatopancreatic necrosis disease (AHPND) epidemic from 2010 to 2013 significantly affected white shrimp (Penaeus vannamei) production in Malaysia. This study aims to determine the status of AHPND in $P$. vannamei culture from detecting PirA/B toxin genes in hepatopancreas tissues and isolation of Vibrio parahaemolyticus for identification of pathogenic strain from major white shrimp producing farms in Malaysia. Bacteria from the hepatopancreas organ were cultured on tryptic soy agar and identified using API ${ }^{\circledR} 20$ NE (bioMérieux, France) for Vibrio species. Confirmation of PirA/B toxin genes in hepatopancreas and $V$. parahaemolyticus isolates were determined by polymerase chain reaction (PCR). Twenty-three $V$. parahaemolyticus isolates were identified from $7.7 \%$ of the analysed samples.

ARTICLE INFO

Article history:

Received: 6 September 2021

Accepted: 29 November 2021

Published: 24 January 2022

DOI: https://doi.org/10.47836/pjtas.45.1.10

E-mail addresses:

padilah@dof.gov.my (Bakar Padilah)

rohaizaasmini@dof.gov.my (Yahya Rohaiza-Asmini)

kuaben01@dof.gov.my (Han-Ming Gan)

gan.gseq@gmail.com (Wan Ahmad Wan Rozana)

wanrozana91@gmail.com (Wan Muhammad Hazim Wan Sajiri)

hazimsajiri@gmail.com (Beng-Chu Kua)

*Corresponding author

Fourteen (14) (4.7\%) were detected with

PirA/B toxin genes from districts of Johor such as Batu Pahat (1) and Kota Tinggi (8), Alor Setar, Kedah (3), Tawau, Sabah (1), and Kuching, Sarawak (1). In contrast, the other nine isolates $(3 \%)$ contained only the plasmid. Genomic and phylogenetic tree analysis of four $V$. parahaemolyticus isolates carrying Pir $A / B$ toxin genes from this study showed that only one strain (Vp14) harbours
\end{abstract}


the $\operatorname{Pir} A / B$ complete genes in addition to displaying full sequence homology and coverage to the pVA1 plasmid. In contrast, other strains (AAT22, IKK3, and PK3) displayed partial sequence homology of plasmid harbouring key genes associated with conjugative transfer function but not the plasmid segments containing PirA/B toxin genes. Hence, this study showed that six farms were negative from AHPND. In contrast, four farms were positive with PirA/B toxin genes in juveniles from Pekan, Pahang (26.7\%), Kuching and Sarikei, Sarawak (10\% respectively), and Alor Setar, Kedah (3.3\%).

Keywords: AHPND, P. vannamei, PirA/B toxin genes, prevalence, $V$. parahaemolyticus

\section{INTRODUCTION}

Acute hepatopancreatic necrosis disease (AHPND) or previously known as early mortality syndrome (EMS), is a bacterial disease caused by a unique strain of Vibrio spp., including Vibrio parahaemolyticus, Vibrio harveyi, Vibrio owensii, Vibrio campbelli, Vibrio punensis, and other possible bacteria that contain $\sim 70-\mathrm{kbp}$ plasmid genes which encode homologous of the Photorhabdus insect-related toxins, PirA/B (Devadas et al., 2019; Lee et al., 2015; Yang et al., 2014). Nucleotide content [guanine-cytosine (GC)] of these two genes is only $38.2 \%$ and is substantially lower than the rest of the plasmid, which suggests that these genes are acquired (Feng et al., 2017; Han et al., 2015). In addition, a plasmid that contains PirA/B toxin genes was found in the pathogenic AHPND strain of $V$. parahaemolyticus (VPAHPND) but was absent in non-pathogenic strain, suggesting $\operatorname{Pir} A / B$ toxin genes as the causative agent for AHPND. These PirA/B toxin genes were also found in Photorhabdus spp., which are gram-negative, luminescent, rod-shaped bacteria members of the family Enterobacteriaceae. In nature, Photorhabdus spp. establish an obligate, symbiotic relationship with entomopathogenic nematode Heterorhabditis spp., which are parasites of insect larvae that have a wide geographic distribution. The first detection of AHPND was reported in China in 2009, Malaysia and Vietnam in 2011, Thailand in 2012, and the Philippines in 2015 (Dabu et al., 2015; Food and Agriculture Organization of the United Nations [FAO], 2013, 2016).

Malaysia produced significant quantities of Penaeus monodon in the early 2000 s but then switched largely to $P$. vannamei until the AHPND epidemic hit the country between 2011 and 2013. Sentinel surveillance based on reports of mortality cases in white shrimp farms from Malaysia showed an increasing number of cases since 2011, with the first report on the east coast of Johor and subsequently in Pahang, Perak, and Penang (Kua et al., 2016). The prevalence of AHPND was 50\% and 26\% in 2011 and 2012, respectively. Confirmation of AHPND was based on observation of clinical signs and the characteristic pathology of acute and terminal stages of AHPND in hepatopancreas organs (Kua et al., 2016). Pale discolouration and atrophy of hepatopancreas accompanied by loose 
shells, empty stomach or discontinuous midgut, and corkscrew swimming behaviour were reported. In addition, mixed bacteria of Vibrio parahaemolyticus, Vibrio fuvialis, Vibrio alginolyticus, Vibrio cholerae, Aeromonas hydrophila, Enterobacter cloacae, Pseudomonas spp., and Photobacterium damselae were isolated from the hepatopancreas.

About $67 \%$ of shrimp production in Malaysia comes from white shrimps (Harkell, 2018). AHPND had caused a significant drop in $P$. vannamei production from 87,000 metric tonnes in 2010 to 67,000 metric tonnes in 2011. A continuous drop in $P$. vannamei production was recorded in 2012 with 48,991.81 metric tonnes (RM61.59 million) to $45,473.74$ metric tonnes (RM86.72 million) in 2013 (Department of Fisheries Malaysia [DOF], 2010, 2011, 2012, 2013). Statistical data in 2018 recorded $P$. vannamei production of 36,007.25 metric tonnes (RM79.8 million) (DOF, 2018). Despite increasing aquaculture areas and shrimp culture farms, diseases and mortalities have been identified as major obstacles to sustainable production. AHPND and hepatopancreatic microsporidians caused by Enterocytozoon hepatopenaei (EHP) have been reported as two emerging diseases from 2010 to 2015 that are usually occurred concurrently and have significantly affected shrimp production due to high mortalities (AHPND) and/or stunted growth (EHP) (FAO, 2017).

Giant tiger shrimp (Penaeus monodon), white leg shrimp (Penaeus vannamei), and oriental/Chinese white shrimp (Penaeus chinensis) are known to be infected with AHPND that is characterised by mass mortalities between $40 \%$ and $100 \%$ in 20-30 days of post-stocking in grow-out ponds (Lightner et al., 2012). Management practices in farms, including pond management and maintenance of good water quality, are known to prevent or avoid stressing shrimp and making them more susceptible to disease. However, low compliance with standards in good biosecurity and good aquaculture practices at farm and hatchery facilities have been identified as major factors favouring the spread of disease from one farm to the other (FAO, 2016). Therefore, shrimp aquaculture needs to continuously develop a systematic approach that implements responsible and science-based farming practices. Hence, the objective of this study is to determine the status of AHPND in P. vannamei culture from detection of $P i r A / B$ toxin genes and bacteria $V$. parahaemolyticus from hepatopancreas organ in relation to several routine management practices of pond culture.

\section{MATERIALS AND METHODS}

\section{Sampling Size and Locations}

A cross-sectional study on the status of AHPND was carried out from major shrimp producing areas in Malaysia, involving ten shrimp farms from 10 districts in Kedah, Penang, Terengganu, Pahang, Johor, Sarawak, and Sabah that started from January to November in 2019. A minimum of 30 pieces of juvenile shrimps/day of culture (DOC) aged less than 30 or between 
31-45 DOC were collected randomly analysed individually. The sampling sites, from various pond cultures (maximum 5 states, districts, months of sampling, and to 6 culture ponds/30 pieces). A total of the number of samples are shown in Table 1. 300 pieces of juveniles were sampled and

\section{Table 1}

A sampling of Penaeus vannamei at the day of culture (DOC) less than 30 days of age, or juveniles between 31-45 days old from 10 locations that show states, districts, months, and number of samples

\begin{tabular}{cccc}
\hline States & District & Month (2019) & Number of samples \\
\hline Kedah & Alor Setar & April & 30 \\
Penang & Bkt. Tambun & February & 30 \\
Terengganu & Setiu & March & 30 \\
Sarawak & Sarikei & May & 30 \\
& Kuching & May & 30 \\
Johor & Batu Pahat & August & 30 \\
& Kota Tinggi & August & 30 \\
Pahang & Pekan & October & 30 \\
Sabah & Kudat & November & 30 \\
& Tawau & November & 30 \\
\hline
\end{tabular}

\section{Bacterial Culture, Isolation, and Identification}

About 210 pieces of juvenile white shrimps aged less than 30 days old in pond culture (Kedah, Terengganu, Johor, Pahang, and Sabah) and 60 pieces of white shrimps (Sarawak) aged between 30-45 days old were tested to detect the presence of bacteria in the hepatopancreas organ. Bacteria were aseptically inoculated via direct streaking onto tryptic soy agar (TSA), which was incorporated with $1.5 \%$ sodium chloride $(\mathrm{NaCl})$ and incubated at $30{ }^{\circ} \mathrm{C}$ for 18 to 24 hours, followed by subculture until pure isolate was obtained.
Vibrio parahaemolyticus bacterial was identified using Gram staining, oxidase test, sensitivity to vibrio static 0129 -disc agent (2, 4-Diamino-6, 7-di-iso-propylpteridine phosphate) $(150 / 10 \mu \mathrm{g})$ and observation of the colour colony on thiosulfate citrate bile salt (TCBS) agar (Austin et al., 1997). A biochemical test for confirmation of Vibrio species was carried out using API $^{\circledR}$ 20 NE Kit (bioMérieux, France). The $V$. parahaemolyticus isolates identified with $98 \%$ to $99.9 \%$ identical to the reference strain in the analytical profile index (API) software database was further tested for the presence of Pir $A / B$ toxin genes using a PCR 
method. An isolate of $V$. alginolyticus was used as rooting for phylogenetic analysis.

\section{DNA Extraction of Hepatopancreas Tissues and Bacteria Cells}

A total of 300 hepatopancreas tissues samples in $95 \%$ alcohol fixation were tested for PirA/B toxin genes using a PCR method. DNA extraction was carried out using the cetyl trimethyl ammonium bromide (CTAB) and dodecyle trimethyl ammonium bromide (DTAB) method (IQ2000 ${ }^{\mathrm{TM}}$, GeneReach Biotechnology Corp., Taiwan). In contrast, bacteria $V$. parahaemolyticus was extracted using G-Spin ${ }^{\mathrm{TM}}$ Genomic Bacteria Extraction Kit (iNtRON Biotechnology, Korea). About $30 \mathrm{mg}$ of hepatopancreas tissues fixed in 95\% alcohol was placed into a $1.5 \mathrm{~mL}$ tube containing $600 \mu \mathrm{L}$ DTAB solution. Tissues were ground with a sterile disposable grinder until they were completely dissolved into DTAB solution. After that, they were incubated at $75{ }^{\circ} \mathrm{C}$ for 5 minutes and cooled down to room temperature. The mixture was vortexed and spun down briefly and was then added with $700 \mu \mathrm{L}$ of chloroform and centrifuged at $12,000 \times g$ for 5 minutes. Next, the upper aqueous phase was transferred into a new $1.5 \mathrm{~mL}$ tube and added $100 \mu \mathrm{L}$ of CTAB solution and $900 \mu \mathrm{L}$ of deionised water. It was then vortexed briefly, incubated at $75^{\circ} \mathrm{C}$ for 5 minutes and centrifuged at $12,000 \mathrm{x} g$ for 5 minutes. Next, the pellet was re-suspended with $150 \mu \mathrm{L}$ dissolving solution, incubated at $75{ }^{\circ} \mathrm{C}$ for 5 minutes and spun at 12,000 $\mathrm{x} g$ for 5 minutes. Finally, the supernatant was transferred into a new $1.5 \mathrm{~mL}$ tube containing $300 \mu \mathrm{L}$ of $95 \%$ ethanol. This procedure was repeated twice, whereby the pellet was washed with $75 \%$ ethanol in the last procedure. The final pellet was dried and dissolved in deionised water or Tris ethylenediaminetetraacetic acid (TE) buffer. Dissolving DNA was stored at $-20{ }^{\circ} \mathrm{C}$ until used for polymerase chain reaction (PCR).

Total genomic DNA from $V$. parahaemolyticus isolate was extracted using G-spin ${ }^{\mathrm{TM}}$ Kit (iNtRON Biotechnology, Korea). About $1 \mathrm{~mL}$ of bacteria cells was harvested from an overnight culture (18-24 hours) at $30{ }^{\circ} \mathrm{C}$ in tryptic soy broth incorporated with $1.5 \% \mathrm{NaCl}\left(\mathrm{OD}_{600}\right.$ $0.8-1.0$ ) by centrifugation at $13,000 \times \mathrm{g}$ for 1 minute. The supernatant was removed, and cells were re-suspended by vortex and tapping. Bacteria cells pellet was extracted according to the manufacturer's instructions. The final collected DNA in a $1.5 \mathrm{~mL}$ tube was measured using a NanoDrop ${ }^{\mathrm{TM}}$ spectrophotometer (DS-11 Series, DeNovix, USA).

\section{PCR Reaction Conditions}

Nested PCR using AP4 primers was followed with some optimisation of annealing temperature using Maxime PreMix i-Taq (iNtRON Biotechnology, Korea) for detecting $\operatorname{Pir} A / B$ toxin genes at $230 \mathrm{bp}$ portion of a sequence, which includes 209 bp of the ToxA or PirA gene sequence plus 12 bp spacer sequence plus 9 bp of succeeding ToxB or PirB gene sequence (Dangtip et al., 2015). First-step PCR was performed using primer AP4-F1 with the sequence: 5'-ATGAGTAACAATATAAAACAT 
Bakar Padilah, Yahya Rohaiza-Asmini, Han-Ming Gan, Wan Ahmad Wan Rozana,

Wan Muhammad Hazim Wan Sajiri and Beng-Chu Kua

GAAAC-3' and AP4-R1: 5' ACGATTTCGACGTTCCCCAA-3', followed by nested PCR using AP4-F2 primer: 5'-TTGAGAATACGGGACGTGGG-3' and A P 4-R2: 5' - G T T A G T CATGTGAGCACCTTC-3'. In the first PCR reaction, $20 \mu \mathrm{L}$ of the total volume reaction mixture was prepared, which consisted of DNA template $2 \mu \mathrm{L}$, AP4-F1 primer $(0.4$ $\mu \mathrm{L} 100 \mathrm{pmol} / \mu \mathrm{L}), \mathrm{AP}-\mathrm{R} 1$ primer $(0.4 \mu \mathrm{L}$ $100 \mathrm{pmol} / \mu \mathrm{L})$, and deionised water $(17.2$ $\mu \mathrm{L})$. Then, amplification was performed with the following parameters: initiation denaturation at $94^{\circ} \mathrm{C}$ for 2 minutes, followed by 35 cycles of $94^{\circ} \mathrm{C}$ for 30 seconds, $53{ }^{\circ} \mathrm{C}$ for 30 seconds, and $72{ }^{\circ} \mathrm{C}$ for 90 seconds, and a final extension at $72{ }^{\circ} \mathrm{C}$ for 2 minutes. For the second step (nested) PCR reaction, $1 \mu \mathrm{L}$ of the final solution from the first-step PCR was diluted with deionised water at the ratio of 1 to $100,2 \mu \mathrm{L}$ of the diluted solution was used with nested primers AP4-F2 $(0.4 \mu \mathrm{L} 100$ $\mathrm{pmol} / \mu \mathrm{L}), \operatorname{AP} 4-\mathrm{R} 2(0.4 \mu \mathrm{L} 100 \mathrm{pmol} / \mu \mathrm{L})$, and deionised water $(17.2 \mu \mathrm{L})$ were used to make up for $20 \mu \mathrm{L}$ of total volume. Then, amplification was performed with initiation denaturation at $94^{\circ} \mathrm{C}$ for 2 minutes, followed by 25 cycles of $94^{\circ} \mathrm{C}$ for 30 seconds, $53{ }^{\circ} \mathrm{C}$ for 30 seconds, $72{ }^{\circ} \mathrm{C}$ for 30 seconds, and a final extension of $72{ }^{\circ} \mathrm{C}$ for 2 minutes. Following PCR, an aliquot of PCR products was analysed in a $1.5 \%$ gel containing green fluorescent dye nucleic acid staining solution (RedSafe $^{\mathrm{TM}}$, iNtRON Biotechnology, Korea).

\section{Sample Preparation for Sequencing and Phylogenomic Tree}

Genomic deoxyribonucleic acid (gDNA) of five Vibrio spp., identified as IKK3, AAT22, PK3, Vp14, and SK6, were sent for sequencing via the iSeq100 Next Generation Sequencing System (GeneSEQ, Malaysia). Genome completeness analysis via BUSCO v4 was assessed for each assembled genome. In addition, protein-coding genes were briefly predicted from the assembly and were assessed for the presence of 1445 conserved genes found in Vibrio (vibrio_odb10). As expected from the high-quality assembly, each genome assembly exhibited genome completeness of $>99.9 \%$. The gDNA was fragmented using a Covaris ultra sonicator to approximately $350 \mathrm{bp}$. The fragmented DNA was end-repaired, adapter-ligated, and PCR-enriched using the NEBNext ${ }^{\mathbb{R}}$ Ultra $^{\text {TM }}$ II DNA Library Preparation Kit (New England Biolabs, USA) according to the manufacturer's instructions. The constructed libraries were normalised and sequenced on NovaSeq 6000 System (Illumina, USA) using a 2 x 150 bp read configuration (Simão et al., 2015).

Vibrio parahaemolyticus genome assemblies in National Center for Biotechnology Information (NCBI) that originated from Malaysia were used to infer a phylogenomic tree of five isolates (IKK3, AAT22, PK3, Vp14, and SK6) obtained from this study. The complete genome sequence of $V$. parahaemolyticus strain MVP1 was used as the reference genome. Each genome was subsequently aligned to 
this reference genome to identify single nucleotide polymorphisms (SNPs) and generate a core SNP alignment. The Snippy v4.6.0 pipeline was used to perform these tasks. First, a maximum-likelihood tree was constructed using the FastTree2 setting, followed by visualisation and annotation in Figtree v1.4.1 (Price et al., 2010).

\section{RESULTS}

\section{Biochemical Confirmation of Bacteria Isolates}

Twenty-three isolates of Vibrio spp. were subjected to a biochemical test to confirm the species using API $^{\circledR} 20$ NE (bioMérieux, France). Isolates Vp14, IKK3, AAT22, and PK3 were identified as V. parahaemolyticus with $90 \%$ to $99.1 \%$ identical to the reference strain in the API system. They were Gramnegative halophilic bacteria, which produced green colony growth on thiosulfate citrate bile salt sucrose (TCBS) agar, was sensitive to vibrio static 0129 -disc agent $(150 / 10 \mu \mathrm{g})$ and exhibited cytochrome oxidase with catalase activity. Enzymatic assays showed that they were nitrate $\left(\mathrm{NO}_{3}\right)$ reductase, tryptophanase, glucose fermentation, gelatinase, and $\beta=$ galactosidase but produced a negative reaction to arginine dihydrolase, urease, and esculin hydrolase. Carbohydrate assimilation showed a positive reaction to D-glucose, L-arabinose, D-mannose, D-mannitol, N-acetyl-D-glucosamine, maltose, D-gluconate, and L-malate but a negative reaction to caprate, adipate, citrate, and phenylacetate. Vibrio alginolyticus
(SK6) produced similar results as $V$. parahaemolyticus isolates, except that it did not produce acid from glucose or decarboxylate $\beta$-galactosidase and did not break up arabinose.

\section{Prevalence of AHPND from Detection of PirA/B Toxin Genes in Hepatopancreas of Penaeus vannamei}

The highest prevalence of AHPND was found in juveniles/day of culture (DOC) of white shrimps from Pekan $(8,26.7 \%)$, Pahang. In contrast, the low prevalence was recorded in juvenile shrimps from Sarikei (3, 10\%), Kuching (3, 10\%), Sarawak, and Alor Setar (1, 3.3\%), Kedah. The 7.3\% of samples (22) were tested positive with $\operatorname{Pir} A / B$ toxin genes with an overall mean prevalence of $5 \%$. Results are shown in Table 2. AHPND prevalence was diagnosed by detecting $\operatorname{Pir} A / B$ toxin genes from hepatopancreas tissues of white shrimps fixed in 95\% alcohol and supported with or without the isolation of $V$. parahaemolyticus isolate that carries $\operatorname{Pir} A / B$ toxin genes. AHPND was not detected in hepatopancreas tissues of juvenile white shrimps from Johor (60), Sabah (60), Terengganu (30), and Penang (30). However, culture isolates of V. parahaemolyticus obtained from white shrimp hepatopancreas at Kota Tinggi (8, $26.7 \%$ ) and Batu Pahat (1,3\%) showed that these strains are pathogenic which carry PirA/B toxin genes. 
Table 2

Detection of AHPND with PirA/B toxin genes from the hepatopancreas of juvenile/DOC white shrimps

\begin{tabular}{lccc}
\hline States & District & $\begin{array}{c}\text { Sample number } \\
(\mathrm{n})\end{array}$ & $\begin{array}{c}\text { Positive sample for PirA/B } \\
\text { toxin genes } \\
\text { (Prevalence, \%) }\end{array}$ \\
\hline Kedah & Alor Setar & 30 & $1(3.3)$ \\
Penang & Bukit Tambun & 30 & - \\
Terengganu & Setiu & 30 & - \\
Johor & Batu Pahat & 30 & - \\
& Kota Tinggi & 30 & - \\
Pahang & Pekan & 30 & $3(26.7)$ \\
Sarawak & Kuching & 30 & $3(10)$ \\
& Sarikei & 30 & - \\
Sabah & Kudat & 30 & - \\
& Tawau & 30 & $15(50)$ \\
\hline Total & & 300 & 5.0 \\
\hline Mean $(\%)$ & & & $3(10)$ \\
\hline
\end{tabular}

Note. Mean (\%): (Number of the sample with PirA/B toxin genes/Total samples) x $100 \%$

\section{Prevalence of Vibrio parahaemolyticus with PirA/B Toxin Genes}

Twenty-three (23) V. parahaemolyticus isolates were obtained from 270 samples of juvenile white shrimps, whereby 14 isolates were detected with $\mathrm{PirA} / B$ toxin genes. AHPND isolates were found in samples from Kota Tinggi $(8,26.7 \%)$ and Batu Pahat (1, 3.3\%), Johor, Alor Setar, Kedah (3, 10\%), and Kudat, Sabah (1, 3\%). Although $V$. parahaemolyticus bacteria from culture media isolation were detected to have PirA/B toxin genes, direct PCR analysis of hepatopancreas tissues fixation (95\% alcohol) of the similar samples failed to detect PirA/B toxin genes from these tissue samples. Virulence of AHPNDcausing V.parahaemolyticus depends on the amount of Pir $A / B$ toxin released and caused cellular damage to hepatopancreas when $V$. parahaemolyticus bacteria initially colonise in the shrimp stomach and eventually reach the hepatopancreas (Han et al., 2015). In this situation, $V$. parahaemolyticus was considered a relatively non-virulent bacterium until it released a potent toxin $(\operatorname{Pir} A / B)$ in the host tissues/hepatopancreas organ or induced the clinical disease condition and mortality in white shrimps. PCR analysis of hepatopancreas tissue of white shrimp sample was negative from Johor (60) and Sabah (60). The detection of PirA/B toxin genes from $V$. parahaemolyticus isolates obtained through the propagation of bacteria cells in the laboratory was not considered a positive case 
for AHPND in this surveillance study but rather for identifying the pathogenic strain. PCR analysis of the cultured cells showed that 13 V.parahaemolyticus AHPND strains were identified from Kota Tinggi (8) and Batu Pahat (1), Johor; Alor Setar (3), Kedah, and Kudat (1), Sabah. Another study has shown that infection of AHPND depends on sufficient bacteria cells count to secrete or release $\operatorname{Pir} A / B$ toxins in the shrimp tissues rather than the number of copies of toxin genes (Tinwongger et al., 2016).

\section{Genomic Sequence of PirA/B Toxin Genes and pVA1 Plasmid}

Five isolates of $V$. parahaemolyticus from Sarawak (Vp14), Kedah (IKK3), Johor (PK3, AAT22), and V. alginolyticus from Sabah (SK6) were subjected to whole- genomic sequences to determine the virulence of local strains obtained from this study. The whole-genome sequences were aligned to the pVA1 plasmid using blastN with an E-value of $1 \mathrm{e}^{-50}$ and subsequently visualised in Blast Ring Image Generator (Alikhan et al., 2011; Dong et al., 2019). Being consistent with the initial PCR screening result, strain Vp14 (Sarawak) was the only strain that harboured the $\operatorname{Pir} A / B$ complete genes in addition to displaying full sequence homology and coverage to the pVA1 plasmid. In contrast, strain AAT22 (Johor) displayed significant sequence homology with at least $50 \%$ length of the plasmid harbouring key genes associated with conjugative transfer function but not the plasmid segment containing the $\operatorname{Pir} A / B$ genes (Figure 1).

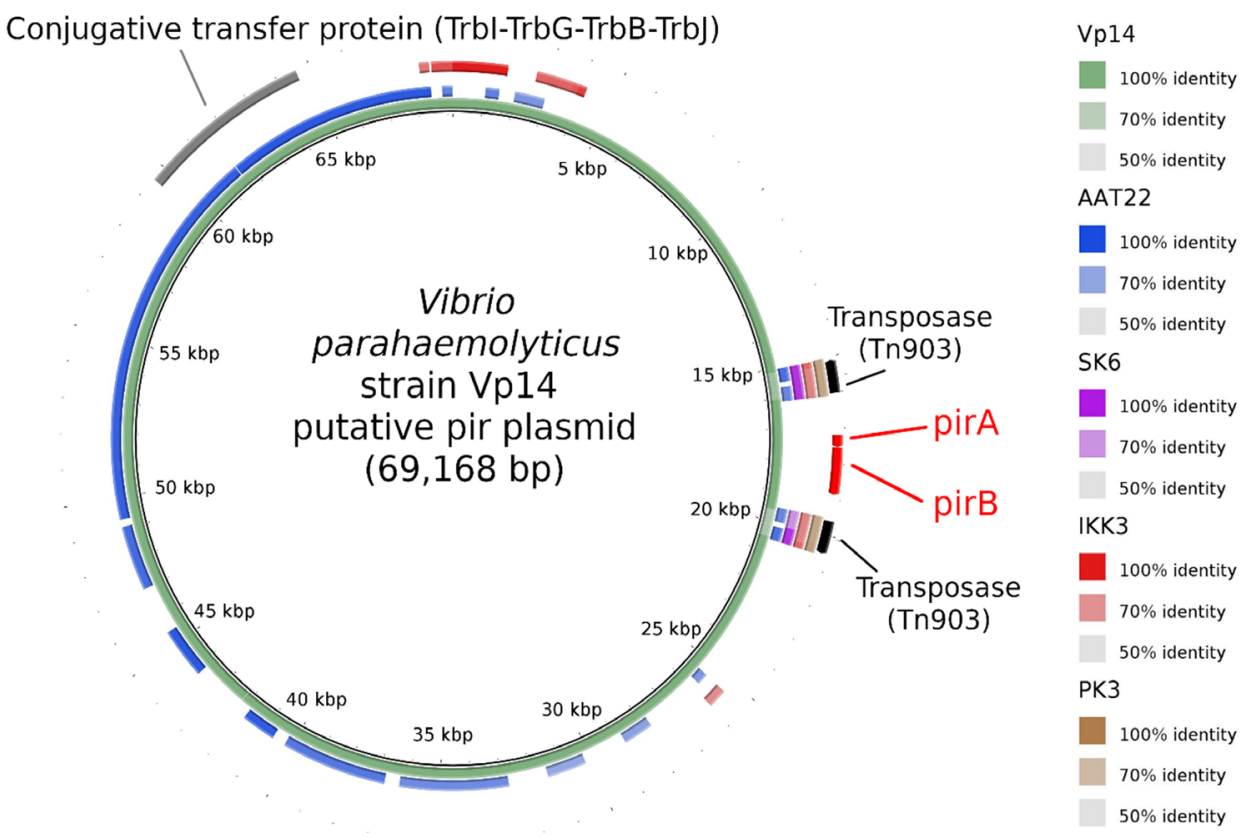

Figure 1. Circular visualization of the pVA1 plasmid and selected genes. Coloured rings indicate a genomic region with significant homology to the strain of interest (Vp14, AAT22, SK6, IKK3, and PK3) 
Bakar Padilah, Yahya Rohaiza-Asmini, Han-Ming Gan, Wan Ahmad Wan Rozana, Wan Muhammad Hazim Wan Sajiri and Beng-Chu Kua

\section{Phylogenomic Tree of Vibrio parahaemolyticus Associated with Genome Assemblies in NCBI from Aquaculture in Malaysia}

Four V. parahaemolyticus isolates, which were identified as Vp14 (Sarawak), AAT22 and PK3 (Johor), IKK 3 (Kedah), and SK6 (Sabah), were identified as $V$. alginolyticus that were subjected to genomic and phylogenetic analysis. The assembled genomes were compared to Vibrio spp. type strains to confirm their taxonomic assignment. Strains AAT22, IKK3, PK3, and $\mathrm{Vp14}$, showed a pairwise average nucleotide identity of more than $98 \%$ to $V$. parahaemolyticus. In contrast, strain SK6 showed an average nucleotide identity of $98.5 \%$ to $V$. alginolyticus and less than $90 \%$ to other tested Vibrio species. Strain SK6 (Sabah) expectedly displayed a long branch length and was thus chosen as the outgroup for rooting, given its taxonomic assignment as $V$. alginolyticus. Strain Vp14 harbours the PirA/B toxin genes formed a monophyletic cluster with high SH-like support of a few MVP strains isolated from a shrimp pond water sample located in Negeri Sembilan in 2016. In contrast, strains IKK3 (Kedah), AAT22 and PK3 (Johor) only shared a relative distance ancestor with some of the publicly available strains, as evidenced by their relatively longer branch length (Figure 2 ). It suggested that they could be novel genomic lineages of $V$. parahaemolyticus, which was not reported previously in Malaysia.

\section{DISCUSSION}

This study showed that grow-out or juvenile white shrimps aged less than 30 days of culture in pond and post-larvae appeared most susceptible to AHPND infection with an overall mean prevalence of $5 \%$ and $4.7 \%$, respectively. AHPND often occurs within 20-30 days of post stocking in grow-out ponds and causes mass mortalities in postlarvae shrimps (De Schryver et al., 2014). Therefore, most farms practise routine screening for major shrimp diseases that are known in aquacultures, such as white spot disease that is caused by white spot syndrome virus (WSD/WSSV), yellow head virus (YHV), taura syndrome virus (TSV), infectious hypodermal and haematopoietic necrosis virus (IHHNV), AHPND, and EHP as parts of prevention programmes in their farms whereby the infected stocks will be destroyed.

This study identified $23 \mathrm{~V}$. parahaemolyticus isolates from $7.7 \%$ of total samples. Fourteen (14) strains of $V$. parahaemolyticus were found to have $\operatorname{Pir} A / B$ toxin genes, whereas nine isolates were detected with plasmid. Gross observation during sampling showed only mild changes in hepatopancreas organs with pale coloured, atrophied, empty midgut, and soft shell in several samples, suggesting that subclinical infection may go unnoticed. However, AHPND infection caused by $V$. parahaemolyticus that produce $\operatorname{Pir} A / B$ toxin genes will usually cause severe pathological changes to hepatopancreas organ, which are shown via degeneration and massive sloughing of hepatopancreas cells, followed 


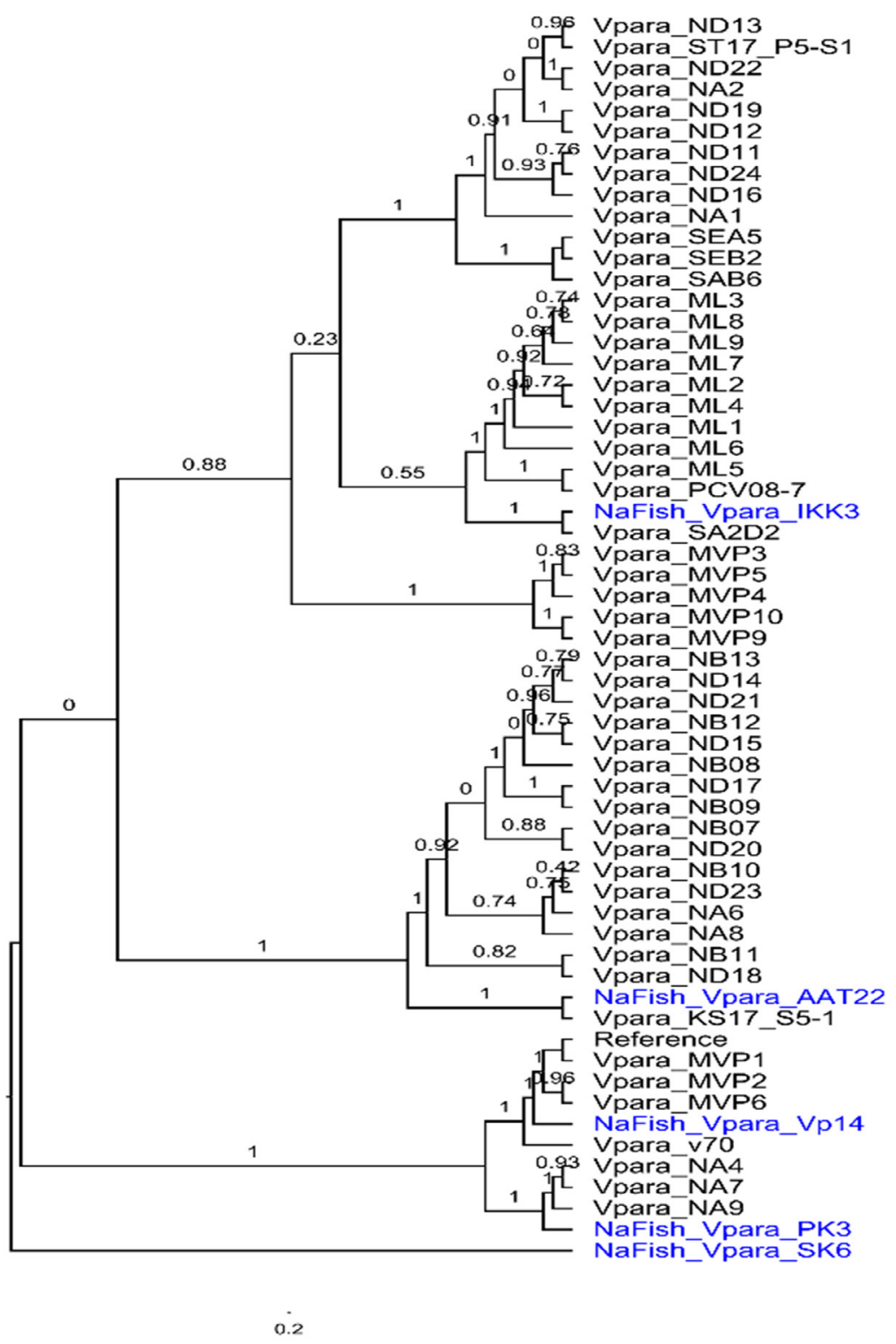

Figure 2. Maximum likelihood tree constructed based on the core SNP alignment of publicly available Malaysian Vibrio parahaemolyticus genomes and NaFish Vibrio genomes (blue labels). Strain SK6 was rooted as the outgroup, given its taxonomic classification as Vibrio alginolyticus. The branch lengths indicate the number of substitutions per site, while the SH-like bootstrap supports values that were indicated by the colour of the nodes. 
by high mortalities in disease outbreaks (Lightner et al., 2012; Nunan et al., 2014). However, typical gross pathological changes associated with clinical disease of AHPND was not observed on-site, and farmers have not reported high mortalities. Nevertheless, the occurrence of $V$. parahaemolyticus bacteria with $\operatorname{Pir} A / B$ toxin genes in the hepatopancreas of shrimp will increase their risk to AHPND under stressful conditions. Routine management practices applied in farms such as regular health screening of stocks, strict biosecurity measures, hygienic practices at the entrance and within farms culture area, and pond management and its water quality are among many factors that impact the management of disease-free culture.

The pVA1 plasmid is the source of the AHPND-causing toxin, whereas $\operatorname{Pir} A / B$ genes, irrespective of other plasmidic factors of pVA1, are sufficient to produce symptoms associated with AHPND (Lee et al., 2015). Culturable cells of $V$. parahaemolyticus local strains were recovered from $-20^{\circ} \mathrm{C}$ storage. Genomic sequencing of four local strains of $V$. parahaemolyticus carrying PirA/B toxin genes showed that only one strain (Vp14) harboured the PirA/B complete genes, which displayed a full sequence of pVA1 virulent plasmid. The risk of AHPND outbreak can be reduced by controlling the Vibrio spp. activities, in particular, $V$. parahaemolyticus cells count. The bacterial concentration ranging $\left(5 \times 10^{4}-5 \times 10^{5} \mathrm{cfu} /\right.$ $\mathrm{ml}$ ) from AHPND strain has been proven to be able to cause significant mortalities to $P$. vannamei from $60 \%$ to $100 \%$ within 3 to 6 days of post infections from the immersion challenge test (Tinwongger et al., 2016). Hence, the virulence of AHPND depends on sufficient bacterial count to release or secrete toxin rather than the number of copies of toxin genes (Tinwongger et al., 2016). Other studies showed that phytoplankton/ green water and nutrient enrichment affect the microbial community in the ecosystem, especially bacterial load and interaction with the shrimp immune responses (De Schryver et al., 2014). Probiotic and/or algae-rich green waters are known to be able to create microbially matured water systems, whereby environments that are primarily colonised by slow-growing harmless bacteria may best guarantee the prevention of AHPND outbreaks (De Schryver et al., 2014). Probiotics and molasses help to increase the diversity of heterotrophic bacteria, including $V$. parahaemolyticus thus, effectively inhibiting pathogens (Bhatnagar \& Pooja, 2013; Hu et al., 2016). Molasses are known to improve water quality, and it is suggested to be used during the nursery and grow-out phase of $P$. vannamei under limited water discharge or close system (Tzachi et al., 2007).

\section{CONCLUSION}

The health status of AHPND from grow-out/ juvenile white shrimps aged less than 30 days of culture was determined through a crosssectional study using a random sampling method. AHPND with the detection of Pir $A / B$ toxin genes and identification of $V$. parahaemolyticus with $P$ ir $A / B$ toxin genes were determined from 10 major shrimp 
producing areas in Malaysia. AHPND with $\operatorname{Pir} A / B$ toxin genes detection from the hepatopancreas of white shrimps was found in Kuching and Sarikei, Sarawak at $10 \%$ prevalence, respectively, followed by $3.3 \%$ in Alor Setar, Kedah, and 26.7\% from Pekan, Pahang. Pir A/B toxin genes of AHPND were not detected in white shrimps from farms in Penang, Johor, Terengganu, and Sabah. Genomic and phylogenetic tree analysis of four $V$. parahaemolyticus isolates carrying PirA/B toxin genes from this study showed that only one strain (Vp14) harboured the $\operatorname{Pir} A / B$ complete genes in addition to displaying full sequence homology and coverage to the pVA1 plasmid. In contrast, other strains (AAT22, IKK3, and PK3) displayed partial sequence homology of plasmid harbouring key genes associated with conjugative transfer function but not the plasmid segments containing the PirA/B toxin genes.

Many factors are known to influence the clinical manifestation of AHPND, such as the presence of $\operatorname{Pir} A / B$ toxin genes and $V$. parahaemolyticus bacteria that carry $\operatorname{Pir} A / B$ toxin genes in hepatopancreas tissues, as well as water quality and bacterial cell counts in pond culture. Health screening through regular observation of shrimp behaviour and health checks for important diseases in shrimp culture provides the best solution for early detection and management of health problems. The risk of spreading the disease to other farms can be prevented through removal and safe disposal of sick or dead shrimps, as well as emergency harvesting if necessary, or destruction of infected stocks as appropriate. Strict biosecurity measures and disinfection have been strictly implemented in almost all farms that the researchers visited or surveyed. This practice is believed to contribute significantly to controlling and preventing AHPND.

\section{ACKNOWLEDGEMENTS}

This work was supported by a research grant from the R\&D Fund (220501-039), the Department of Fisheries Malaysia (DOF), and the Ministry of Agriculture Malaysia (MOA). The authors want to thank the Director of Fisheries Research Institute (FRI), Batu Maung, Dr Zainoddin Jamari, for providing financial and moral support. The authors would also like to express their sincere gratitude to all farmers, company managers, officers, and staff from various States of Fisheries Department (Pejabat Perikanan Negeri), Biosecurity and Aquaculture Division from Kedah, Terengganu, Johor, Pahang, Sarawak and Sabah for their active participation and continuous support throughout the process of conducting this study.

\section{REFERENCES}

Alikhan, N. F., Petty, N. K., Ben-Zakour, N. L., \& Beatson, S. A. (2011). BLAST Ring Image Generator (BRIG): Simple prokaryote genome comparisons. BMC Genomics, 12(1), 402. https://doi.org/10.1186/1471-2164-12-402

Austin, B., Austin, D. A., Blanch, A. R., Cerdà, M., Grimont, F., Grimont, P. A. D., Jofre, J., Koblavi, S., Larsen, J. L., Pedersen, K., Tiainen, T., Verdonck, L., \& Swings, J. (1997). A comparison of methods for the typing of 
fish-pathogenic Vibrio spp. Systematic and Applied Microbiology, 20(1), 89-101. https://doi. org/10.1016/S0723-2020(97)80053-7

Bhatnagar, A., \& Pooja, D. (2013). Water quality guidelines for the management of pond fish culture. International Journal Environmental Science, 3(6), 5-30. https://doi.org/10.6088/ ijes.2013030600019

Dabu, 1. M., Lim, J. J., Arabit, P. M. T., Orense, S. J. A. B., Tarbadillo, J. A., \& Corre, V. L. (2015). The first record of acute hepatopancreatic necrosis disease in Philippines. Aquaculture Research, 48(3), 792-799. https://doi.org/10.1111/ are. 12923

Dangtip, S., Sirikharin, P., Sanguanrut, S., Thitamadee, K., Sritunyalucksana, S., Taengchaiyaphum, R., Mavichak, P., Proespraiwong, P., \& Flegel, T. W. (2015). AP4 method for two-tube nested PCR detection of AHPND isolates of Vibrio parahaemolyticus. Aquaculture Representative, 2, 158-162. https://doi.org/10.1016/j. aqrep.2015.10.002

De Schryver, P., Defoirdt, T., \& Sorgeloos, P. (2014). Early mortality syndrome outbreak: A microbial management issue in shrimp farming? PLOS Path, 10(4), e1003919. https://doi.org/10.1371/ journal.ppat.1003919

Department of Fisheries Malaysia. (2010). Perangkaan Perikanan Tahunan 2010 [Annual fisheries statistics 2010]. DOF. https://www.dof.gov.my/ en/resources/fisheries-statistics-i/

Department of Fisheries Malaysia. (2011). Perangkaan Perikanan Tahunan 2011 [Annual fisheries statistics 2011]. DOF. https://www.dof.gov.my/ en/resources/fisheries-statistics-i/

Department of Fisheries Malaysia. (2012). Perangkaan Perikanan Tahunan 2012 [Annual fisheries statistics 2012]. DOF. https://www.dof.gov.my/ en/resources/fisheries-statistics-i/
Department of Fisheries Malaysia. (2013). Perangkaan perikanan tahunan 2013 [Annual fisheries statistics 2013]. DOF. https://www.dof. gov.my/en/resources/fisheries-statistics-i/-

Department of Fisheries Malaysia. (2018). Perangkaan tahunan perikanan 2018 jilid 1 [Annual fisheries statistics 2018 volume 1]. DOF. https://www. dof.gov.my/en/resources/i-extension-en/annualstatistics/

Devadas, S., Banerjee, S., Yusoff, S. F. M., Bhassu, S., \& Shariff, M. (2019). Review: Experimental methodologies and diagnostic procedures for acute hepatopancreatic necrosis disease (AHPND). Aquaculture, 499, 389-400. https:// doi.org/10.1016/j.aquaculture.2018.06.042

Dong, X., Song, J., Chen, J., Bi, D., Wang, W., Ren, Y., Wang, H., Wang, G., Tang, K. F. J., \& Wang, X. (2019). Conjugative transfer of the pVA1-type plasmid carrying the PirAB vp genes results in the formation of new AHPNDcausing Vibrio. Frontiers in Cellular and Infection Microbiology, 195(9), 1-11. https://doi. org/10.3389/fcimb.2019.00195

Feng, B., Liu, H., Wang, M., Sun, X. H., Pan, Y., \& Zhao, Y. (2017). Diversity analysis of acute hepatopancreatic necrosis disease-positive Vibrio parahaemolyticus strains. Aquaculture and Fisheries, 2(6), 278-285. https://doi. org/10.1016/j.aaf.2017.10.001

Food and Agriculture Organization of the United Nations. (2013). FAO/MARD technical workshop on early mortality syndrome (EMS) or acute hepatopancreatic necrosis syndrome (AHPNS) of cultured shrimp. FAO. https://www.fao.org/3/ i3422e/i3422e00.htm

Food and Agriculture Organization of the United Nations. (2016). Second international technical seminar/workshop on acute hepatopancreatic necrosis disease (AHPND) there is a way forward!. FAO. https://www.fao.org/documents/ card/en/c/28b6bd62-5433-4fad-b5a 1 8ac61eb671b1/ 
Food and Agriculture Organization of the United Nations. (2017). FishStatJ-Software for fishery and aquaculture statistical time series. FAO.

Han, J. E., Tang, Kathy F. J., Tran, Loc H., \& Lightner, D. V. (2015). Photorhabdus insect-related (Pir) toxin-like genes in a plasmid of Vibrio parahaemolyticus, the causative agent of acute hepatopancreatic necrosis disease (AHPND) of shrimp. Disease Aquatic Organisms, 113, 33-40. https://doi.org/10.3354/dao02830

Harkell, L. (2018). Half of shrimp farmers in key Malaysia region switch to black tiger: Seafood business news from beneath the surface. https:// www.undercurrentnews.com/2018/08/27/halfof-malaysian-shrimp-farmers-in-key-regionswitch-to-black-tiger/

Hu, X. J., Cao, Y. C., Wen, G. L., Zhang, X. Y., Xu, Y., Xu, W., \& Li, Z. J. (2016). Effect of combined use of Bacillus and molasses on microbial communities in shrimp cultural enclosure systems. Aquaculture Research, 48(6), 26912705. https://doi.org/10.1111/are.13101

Kua, B. C., Ahmad, I. A. R., Siti-Zahrah, A., Irene, J., Norazila, J., Nik-Haiha, N. Y., Fadzilah, Y., Mohammed, M., Siti-Rokhaiya, B., Omar, M., \& Teoh, T. P. (2016). Current status of acute hepatopancreatic necrosis disease (AHPND) of farmed shrimp in Malaysia. In Addressing Acute Hepatopancreatic Necrosis Disease (AHPND) and Other Transboundary Diseases for Improved Aquatic Animal Health in Southeast Asia: Proceedings of the ASEAN Regional Technical Consultation on EMS/AHPND and Other Transboundary Diseases for Improved Aquatic Animal Health in Southeast Asia (pp. 55-59). Southeast Asian Fisheries Development Center.

Lee, C. T., Chen, I. T., Yang, Y. T., Ko, T. P., Huang, Y. T., Huang, J. Y., Huang, M. F., Lin, S. J., Chen, C. Y., Lin, S. S., Lightner, D. V., Wang, H. C., Wang, A. H., Hor, L. I., \& Lo, C. F. (2015). The opportunistic marine pathogen
Vibrio parahaemolyticus becomes virulent by acquiring a plasmid that expresses a deadly toxin. Proceedings of the National Academy of Sciences, 112(34), 10798-10803. https://doi. org/10.1073/pnas.1503129112

Lightner, D. V., Redman, R. M., Pantoja, C. R., Noble, B. I., \& Tran, Loc H. (2012). Early mortality syndrome affects shrimp in Asia. Global Aqua Advocate, 15(1), 40.

Nunan, L., Lightner, D. V., Pantoja, C., \& GomezJimenez, S. (2014). Detection of acute hepatopancreatic necrosis disease (AHPND) in Mexico. Disease Aquatic Organisms, 111, 81- 86. https://doi.org/10.3354/dao02776

Price, M. N., Dehal, P. S., \& Arkin, A. P. (2010). FastTree 2 - Approximately maximumlikelihood trees for large alignments. PLOS One, 5(3), e9490. https://doi.org/10.1371/journal. pone. 0009490

Simão, F. A., Waterhouse, R. M., Ioannidis, P., Kriventseva, E. V., \& Zdobnov, E. M. (2015). BUSCO: Assessing genome assembly and annotation completeness with single-copy orthologs. Bioinformatics, 31(19), 3210-3212. https://doi.org/10.1093/bioinformatics/btv351

Tinwongger, S., Nochiri, Y., Thawonsuwan, J., Nozaki, R., Kondo, H., Awasthi, S. P., Hinenoya, A., Yamasaki, S., \& Hirono, I. (2016). Virulence of acute hepatopancreatic necrosis disease PirAB-like relies on secreted proteins not on gene copy number. Journal Applied Microbiology, 121(6), 1755-1765. https://doi.org/10.1111/ jam. 13256

Tzachi, M. S., Susmitas, P., Mike, S., Abduk-Mehdi, A., Josh, M. B., Rodrigo, V. A., Zarrein, A., Margasanto, H., Ami, H., \& David, L. B. (2007). Use of molasses as carbon source in limited discharge nursery and grow-out systems for Litopenaeus vannamei. Aquacultural Engineering, 36(2), 184-191. https://doi. org/10.1016/j.aquaeng.2006.10.004 
Bakar Padilah, Yahya Rohaiza-Asmini, Han-Ming Gan, Wan Ahmad Wan Rozana, Wan Muhammad Hazim Wan Sajiri and Beng-Chu Kua

Yang, Y. T., Chen, I. T., Lee, C. T., Chen, C. Y., Lin, S. S., Hor, L. I., Tseng, T. C., Huang Y. T., Sritunyalucksana, K., Thitamadee, S., Wang, H. C., \& Lo, C. F. (2014). Draft genome sequences of four strains of Vibrio parahaemolyticus three of which cause early mortality syndrome/acute hepatopancreatic necrosis disease in shrimp in China and Thailand. Genome Announcement, 2(5), e00816-14. https://doi.org/10.1128/ genomeA.00816-14 